\title{
Response to Commentary on Sara, A Social Phobia Client with Sudden Change After Exposure Exercises in Intensive Cognitive-Behavior Group Therapy: A Case-Based Analysis of Mechanisms of Change
}

\section{Further Reflections on the Complexities of Therapeutic Change Mechanisms in a Case Study of Social Phobia}

\author{
ESBEN HOUGAARD ${ }^{\mathrm{a}, \mathrm{c}}$, VICKI L. JENSEN ${ }^{\mathrm{a}}$, \& DANIEL B. FISHMAN ${ }^{\mathrm{b}}$ \\ ${ }^{a}$ Department of Psychology and Behavioural Sciences, University of Aarhus, Denmark \\ b \\ Graduate School of Applied and Professional Psychology, Rutgers University, U.S.A. \\ c Correspondence concerning this article should be addressed to Esben Hougaard, Department of Psychology and \\ Behavioural Sciences, University of Aarhus, Universitetsparken, Bartholins Allé 9, 8000 Aarhus C, Denmark. \\ Email: esbenh@psy.au.dk
}

\begin{abstract}
The paper is a response to a commentary by Rogojanski and Rego (2013) on our case study of Sara (Jensen, Hougaard, \& Fishman, 2013). Sara was a client who achieved a remarkable and durable change in her longstanding social phobia (SP) after short-term group cognitive-behavior therapy (CBT). Our response deals with the following topics: (1) safety behavior; (2) the idiographic arrangement of exposure as behavioral experiments; (3) acceptance as a mechanism of action in CBT; (4) the specific format of the Aarhus treatment program; and (5) recent advances in quantitative research on change mechanisms in CBT for anxiety disorders. We conclude that Rogojanski and Rego's commentary and our further reflections underline the original conclusion from our case study: that generally, change mechanisms in psychotherapy are highly complex, and that specifically, the data from Sara's case could be consistent with several disparate theories of change mechanisms in CBT, revealing a high degree of overlap and intertwining among the theories.
\end{abstract}

Key words: social phobia; cognitive-behavior therapy; group therapy; case study; clinical case study; change mechanisms; psychotherapy process

We want to thank Jenny Rogojanski and Simon Rego (2013) for their most interesting comments and reflections on our case study on Sara (Jensen, Hougaard \& Fishman, 2013). Their commentary primarily deals with clinical and theoretical aspects of cognitive-behavior therapy (CBT) for social phobia (SP) with a focus on safety behavior, idiographic arrangement of exposure as behavioral experiments ("Interrogating the social environment"), acceptance as a mechanism of action in CBT, and the specific format of the Aarhus treatment program. We will successively address these topics and add an update on quantitative group studies of change mechanisms in CBT for anxiety disorders. 


\section{SAFETY BEHAVIOR}

The term "safety behavior" or "safety seeking behavior" was introduced in the CBT literature by the Oxford Group consisting of, among others, Paul Salkovskis and David Clark in the 1990's, although the related concept of "safety-signals" has a much longer history within behavior theory, dating back to Herbert O. Mowrer around 1960. According to Mowrer's (1960) reformulated two-factor theory of fear learning, conditioned avoidance responses are so highly persistent and difficult to extinguish, not only because the conditioned stimuli function as negative reinforcers signaling absence of threat, but also because they have acquired positive reinforcement value as safety-signals, that is signals of relief or "hope.” Safety-signals are objects that due to their conditioning history have acquired calming qualities, and therefore can be used for fear reduction in phobic situations. Rachman (1983) suggested a specific "safetysignal therapy" for agoraphobia with exposure directed toward a safe person or the home, instead of, as is usually done, away from such safety-signals. Barlow (1988, p. 381) made a list of safety-signals among clients with panic disorder/agoraphobia, with unused or even empty pill containers as by far the most common "talisman," followed by bringing water or food into the feared situations. According to Barlow, it is important during exposure treatment to wean clients from their use of safety-signals in order not to make fear extinction dependable on their presence (i.e., the patient learns to be in the feared situations only in the presence of the safety-signal). As mentioned in Rogojanski and Rego's commentary, Rachman has continued to consider the possible positive effects of including "safety behavior" (the cognitive term that he now uses) in exposure exercises with anxiety disordered clients (Rachman et al., 2008).

In 1991 Salkovskis defined "safety-seeking behavior" broadly as behavior intended to prevent the feared outcomes or consequences perceived as threatening, including both avoidance of and escape from feared situations. While safety-signals were supposed to have their origin in conditioning experiences, Salkovskis suggested a cognitive formulation with a "logical" connection between the individual's catastrophic beliefs and their use of safety-seeking behavior; as an example, the panic disordered individual may—quite rationally as seen from his or her perspective-hurry out of from, or quickly sit down in the supermarket to prevent fainting after experiencing symptoms of dizziness. Safety-seeking behavior does, however, have the unfortunate consequence of hindering falsification of the catastrophic beliefs underlying the anxiety, since the prevention of the catastrophe is attributed to the use of the behavior. Salkovskis speaks of a "near miss" attribution a la: "I would have fainted, had I not quickly sat down!”

Salkovskis, Clark and Gelder (1996) used the now more common term "safety behavior" interchangeably with the term "safety-seeking behavior" and distinguished among three types of behavior in the situation: avoidance, escape, and subtle avoidance. It is the subtle avoidance behavior in the situation that is now most commonly equated with safety behavior. Safety behavior in the sense of subtle avoidance behavior is considered a major target of CBT for anxiety disorders by the Oxford Group. Since they define safety behavior with reference to both their intended purpose (avoiding disaster) and their functional consequences (preventing disconfirmation of catastrophic beliefs), it follows (1) that safety behavior are idiographically related to the individual's particular thoughts; and (2) that they should be considered countertherapeutic. Point 1 indicates that topographic lists of safety behavior may have limited validity, 
while point 2 raises the important question of how to differentiate between problematic safety behavior and healthy coping strategies (see Thwaites \& Freeston, 2005). Salkovskis (1991) suggested a differentiation in which safety behaviors are aimed at avoiding the imagined disaster (and preventing its disconfirmation), while coping responses are aimed at dealing with the anxiety alone (p. 16) while having the consequence of reducing anxiety in the longer turn (p. 12). The distinction is, however, not clear-cut as revealed in discussions of therapeutic methods aimed at reducing anxiety, for instance controlled breathing or progressive relaxation, as possible safety behaviors. Besides, identical behavior may in some contexts be adaptive while maladaptive in others, as with over-preparation that may be expedient for an important public speech, but not for small talks in daily life.

According to Clark (2005; Clark \& Wells, 1995), safety behavior among individuals with SP may have other unfortunate consequences than preventing disconfirmation of catastrophic beliefs. Some safety behaviors can create SP symptoms, as when wearing a jacket to hide underarm sweating creates more sweating; some can further draw other people's attention to the symptoms, as when trying to cover blushing with a raised arm may be even more eye-catching than the blushing; and some can partly create the feared social situation, as when avoiding eye contact in a conversation can make the individual appear queer.

Clark and Wells (1995) proposed what may be considered a special form of safety behavior in individuals with SP, namely, their self-focused attention with monitoring of their internal states as a basis for their creation of an image of themselves as seen from an observer point of view. The self-monitoring with its hyper-vigilance for somatic and cognitive anxiety symptoms may further increase the subjective intensity of such symptoms. It could be added that attempts to voluntarily repress autonomic anxiety symptoms (that may also be a form of safety behavior although not often considered as such) paradoxically are likely to increase thempossibly due to an experience of lack of control that may further increase anxiety (Barlow, 1988). Other theories of the negative consequences of safety behavior have suggested that their dampening of anxiety might hinder emotional processing at a higher emotional level (Barlow, Allen \& Choate, 2004); that they may negatively influence the experience of self-efficacy (Casey, Oei \& Newcombe, 2004); or that they may occupy attention and thereby reduce the individual's cognitive resources to process disconfirming information (Sloan \& Telch, 2002).

Theoretical conceptions of safety behavior are thus rather complex-certainly more so than outlined in the case study of Sara. Although the functional definition of safety behavior by the Oxford Group literally begs the question of their possible positive therapeutic value, Rogojanski and Rego (2013) are certainly correct in pointing out that the distinction between safety behavior and adaptive coping is difficult, and that suggested safety behaviors from topographic lists have sometimes not stood an empirical test of their supposed negative consequences. It is also likely that safety behavior might sometimes play a temporary facilitative role in the process of exposure as suggested by Rachman and colleagues (2008) as well by others. In our manual for clients and therapists (Hougaard, 2006) we consider the possible benefits of using "aids" and "backdoors" during difficult exposure exercises. Examples are diaphragmatic breathing, or distraction, or temporarily leaving the situation at a certain, predefined level of anxiety, although we generally recommend staying in the situation and accepting the anxiety as the best exposure strategy. 
Ideally, the idiographic functional analysis of a client's safety behavior should consider all behavior and their potential negative consequences, although in practice this is not possible. As is most often the case, Sara's fears were multi-faceted with many more fears than those included in the case-formulation (see. Sara's Problem List in Table 2, Jensen et al., 2013, p. 323), and so also were, most likely, her use of safety behavior. A case-formulation is a hypothetical formulation of predisposing and maintaining factors influencing an individual's psychological problems meant to function as a practical guide for therapeutic work (Eells, Lombart, Kendjelic, Turner \& Lucas, 2005). We do believe that the case-formulation of Sara functioned quite well as a practical guide, although we agree with Rogojanski and Rego (2013) that a theoretically more fully outlined case-formulation of Sara's safety behavior would have been preferable.

\section{DESIGN OF BEHAVIORAL EXPERIMENTS}

We fully agree that exposure exercises should be designed as behavioral experiments aimed at testing the client's specific catastrophic predictions, corresponding to what Clark (2005) has called "interrogating the social environment." Since most of the major theories of how exposure works stress expectation violation (see Jensen et al., 2013), it seems natural to suppose that it should be preferable to arrange exposure exercises as behavioral experiments—a supposition with some, although limited empirical support (McMillan \& Lee, 2010). Behavioral experiments with clear pre-exercise client prediction of what would happen, and clear feedback to test the prediction after the experiment are the usual way to conduct exposure exercises at the Aarhus University Clinic. In Sara's behavioral experiments, video playback and group discussion apparently functioned well as corrective feedback on her performances.

Clark (2005) mentions a peculiar way of interrogating the environment, called "widening the bandwidth,"that is aimed at helping clients discover the typically wide range of acceptable ways of behaving in social situations by purposely breaking their own rules; for instance by deliberately spilling wine, or by using water to dampen armpits. Some of these strategies are quite similar to so-called paradoxical therapeutic methods, once popular within systemic psychotherapy, and they are described under the headline of "Paradoxical Methods" in our manual (Hougaard, 2006). Specifically for SP clients with blushing phobia, it is proposed that they try to redden as much as possible in a social situation. The explanation given for this exercise is that attempts at voluntarily increasing autonomic reactions, like blushing or shaking, can make one feel less out of control and scared; and it can also contribute to creating a distance from the problem through humor. Dating back to 1925, the existential therapist Victor Frankl (1967) suggested such a "paradoxical intention" strategy to counteract negative response expectations about feared autonomic reactions like blushing, also referring to the role of humor in its mechanism of action.

In the case of Sara, a paradoxical strategy was actually pursued in the student-arranged behavioral experiment the second day of her group therapy, where Sara voluntarily tried, although unsuccessfully, to provoke her blushing by running up stairs prior to the group gathering. We do not believe that Sara would have accepted the a more provocative experiment like attending a meeting while wearing excessive makeup to simulate blushing, and also such simulation seemed superfluous for Sara, who easily blushed. Generally, it is our experience that strategies to widen the bandwidth should be cautiously used with SP clients, making sure that 
they do not excessively feel they are making fools of themselves. For Sara, especially, we were cautious in this regard due to her traumatic memory of being exposed to ridicule by her teacher in elementary school.

\section{ACCEPTANCE AS A MECHANISM OF ACTION IN CBT}

In line with the Rogojanski and Rego (2013), we also primarily think of "third wave" mindfulness and acceptance strategies as compatible with CBT that may lead to improved interventions for some problems or disorders. Specifically, as suggested by Hofmann and Asmundson (2008), cognitive reappraisal may be an adaptive antecedent-focused emotionregulation strategy, employed before the emotion fully unfolds, whereas acceptance strategies from the third wave may be used to counteract maladaptive response-focused emotionregulation strategies, such as emotional suppression, used after the emotion has been generated. Cognitive reappraisal can be an effective therapeutic strategy when used prior to a negative emotional response, for instance as preparation for an exposure exercise, while it may be useless or even counter-therapeutic when used at the height of an emotional experience, or to combat rumination or worrying connected with longstanding and persistent negative emotions. This may be a reason why mindfulness strategies have especially gained footing within the treatment of rumination in depression (e.g., Zegal, Teasdale \& Williams, 2002; Martell, Dimidjian \& Herman-Dunn, 2010), or worrying in generalized anxiety disorder (e.g., Romer \& Orsillo, 2002).

That acceptance of her blushing played such an important role in the treatment of Sara may be seen as a consequence of her desperate attempts to control and suppress her blushing. Since blushing is an autonomic response, such an attempt is doomed to failure, with further experience of uncontrollability, anxiety, and blushing likely to escalate in a vicious circle. Acceptance might in such a situation be the only efficient strategy to break the vicious circle by achieving what might be called a type of "meta-control” of her blushing by deliberately letting it happen. It should be noted that the CBT for Sara could be seen as rather ordinary, if her attempt at control of her reddening tendency is considered a form of safety behavior. The behavioral experiments could here be viewed as a test of the functionality of her safety behavior's intended aim to prevent her imagined disaster.

\section{THE SPECIAL FORMAT OF THE AARHUS TREATMENT PROGRAM}

The treatment program offered at the Anxiety Clinic in Aarhus is distinctive in offering a combination of an intensive week of group therapy together with individual treatment, which for many SP clients was rather extensive. It was also the focus of discussion of a prior PCSP publication, an embedded case study of nine SP clients in the same treatment program (Hougaard et al., 2008; Hougaard, 2008). In commenting in PCSP on the study, both Edwards (2008) and Huppert (2008) questioned the use of group treatment for SP, since studies by Clark and his colleagues have found individual CBT to be more efficacious than a group version of the same therapy (Stangier, Heidenreich, Peitz, Lauterbach, \& Clark, 2003), as well as a 41-hour intensive group treatment program (Mörtberg, Clark, Sundin \& Wisted, 2007). It should be added that the recent practice guideline developed by the National Institute for Health and Clinical Excellence (NICE, 2013) in the UK recommends individual CBT for SP, especially based on the Clark and Wells (1995) model, and not group CBT. 
The intensive group treatment was developed partly due to its proposed educational value, since it makes it possible for inexperienced students to watch clinicians work with many clients, and to gradually themselves take over treatment responsibility. The treatment format can hardly be considered cost-effective when considering the therapist resources involved, but this is a matter of less concern in a training clinic since students have more time for their rather few clients. Results from our study benchmarked well with prior results achieved by different authors in individual CBT for SP (Hougaard, 2008), although they did not quite measure up with those achieved specifically by Clark and Wells in their individual CBT program. Moreover, the intensive group-week resulted in particularly fast symptomatic declines for most clients, thus rather quickly relieving their suffering (Hougaard et al., 2008).

Rogojanski and Rego (2013) are quite positive about the use of group and massed treatment, as both treatment formats have successfully been used in CBT for other anxiety disorders. Their cited research does not, however, cover SP, where group treatment may be less effective. This is a puzzling result, since it was with this type of client that such treatment was traditionally considered especially pertinent. The reasons for the probable inferiority of group CBT for SP are not obvious, but maybe Rogojanski and Rego are correct in suggesting that the group in itself can function as a form of safety behavior or safety-signal, that is, as a secure place in which to interact with others where learned skills are not easily generalized to the "real” outside world.

The intensive, massed treatment format may have advantages for some clients in that it speeds up improvement, but it can be difficult to implement in ordinary treatment in the clinic. Although Edna Foa originally preferred an intensive, daily 3-week treatment program for obsessive-compulsive disorder, she and her colleges compared it to a twice-weekly program with an argument that such a program is more easily transportable to an ordinary clinical setting (Abramowitz, Foa \& Franklin, 2003). The Aarhus CBT research group once compared an intensive 2-week group CBT program for panic disorder to our standard group program dispersed over 13 weeks with comparable short- and long-term results (Bohni, Spindler, Arendt, Hougaard \& Rosenberg, 2009). The intensive program has, however, not been used since then, as it has been difficult to implement it in the daily routine schedules at the clinic! Intensive shortterm programs are, however, easier to implement in a university training clinic.

\section{QUANTITATIVE STUDIES ON CHANGE MECHANISMS}

The primary aim of our paper (Jensen et al., 2013) was to illuminate the contribution of the pragmatic case method to the study of micro-level change mechanisms in psychotherapy, as a supplement to quantitative research on mediators. Since our case study was completed in 2009, and since quantitative mediation research has witnessed an upsurge in the past four years, a short update on such research is in order.

To recapitulate, a mediator or mediating variable is an operationalization of a construct in a theory of change that statistically accounts for at least part of the relationship between the independent variable (treatment) and the dependent variable (outcome). Following Figure 1 (Baron \& Kenny (1986), to conclude that a variable functions as a mediator of psychotherapeutic change requires that it can be shown: (1) that treatment causes change in the mediator variable (path $a$ in Figure 1); (2) that change in the mediator variable is associated with change in 
outcome (path $b$ ); and either (3a) that the outcome of treatment (path $c$ ) is reliably reduced (to $c$ ') after taking account of the influence of the mediator(Baron \& Kenny, 1986); or (3b) that there is a direct interaction effect of path $a$ and path $b$ (the product term, "axb," that corresponds to $c$ minus c') on outcome (Sobel, 1982). Fulfillment of these three conditions are sometimes considered sufficient for a formal mediation analysis, although (4) the direction of causality between change in the proposed mediator and outcome should also be taken into account by establishing a time-line of change in the variables; that is, it should be documented that change in the mediator took place prior to change in outcome (Kraemer, Wilson, Fairburn \& Agras, 2002).

Smits, Julian, Rosenfield and Powers (2012) recently conducted a systematic review of studies on threat reappraisal, involving change of dysfunctional beliefs, as a mediator of symptom change in CBT for anxiety disorders, evaluating the studies according to criteria like the above mentioned. Based on their review of 25 studies, they concluded that threat reappraisal was documented to be related to symptom improvement in CBT for anxiety disorders, but that few of the studies met most of the criteria for mediation necessary to conclude that it actually causes change. Besides, due to a lack of documented specificity of threat reappraisal as a mediator in the studies (as compared with other proposed mediators), the possibility cannot with certainty be excluded that it functioned as a proxy for other third variables.

Another new systematic review and meta-analysis dealt with anxiety control or panic self-efficacy as a mediator in CBT for panic disorder/agoraphobia with altogether 33 studies with data of relevance for at least one of the four above-mentioned questions (Fentz, Arendt, O'Toole, Hoffart \& Hougaard, submitted). Again, although there were few studies that answered most of the questions, the results convincingly showed that change in panic self-efficacy was related to change in CBT for panic disorder/agoraphobia. Furthermore, results revealed that the influence of panic self-efficacy generally was on a par with that of threat reappraisal; for instance, metaanalyses of results relevant for answering questions 1 and 2 showed quite comparable effect sizes for the mediators in regard to paths $a$ and $b$ in Figure 1. Studies with repeated measurements of both mediator and outcome during therapy have, however, most often also found support for the reverse relationship (i.e., prior symptomatic change causes change in the mediator), indicating a reciprocal causal relationship (e.g., Fentz, Hoffart, Jensen, Arendt, O'Toole, Rosenberg \& Hougaard, 2013; Hoffart, Borge, Sexton, \& Clark, 2009; Meuret, Seidel, Rosenfield, Hofmann, \& Rosenfield, 2012).

In a small, intensive time-sampling study with single case time-series analyses for 12 individual patients with panic disorder/agoraphobia, Bouchard and colleagues found individual trajectories of change in that change in panic self-efficacy mediated change in six cases; catastrophic beliefs did so in three cases; while both of the cognitive mediators were involved in three cases (Bouchard, Gauthier, Nouwen, Ivers, Vallieres, Simard et al., 2007).

In sum, recent quantitative mediational studies show growing evidence for some of the major theories of change in CBT for anxiety disorders, although at this point there seems little specificity of results, indicating that several mediators are at work. Studies have most often found a reciprocal causal relationship between mediator and symptomatic improvement; that is, change in the mediator both causes and is caused by symptom improvement. The study by Bouchard and colleges (2007), although small in number of clients, offers intriguing evidence that individual trajectories of change, with different mediators of change for different clients, 
best reflect the actual clinical phenomena. Such results from quantitative studies on change mechanisms are fully in line with conclusions based on our case study of Sara (Jensen et al., 2013).

\section{CONCLUDING COMMENTS}

We are grateful for the opportunity to reply and reflect on the keen commentary by Rogojanski and Rego (2013) regarding our case study. It is reassuring to know that we fully agree on almost all of their clinical and theoretical suggestions. We appreciate their concurring conclusion that the data from Sara's case could be theoretically consistent with several disparate theories of anxiety disorders and thus interpreted differently based on these various theoretical perspectives. Specifically, their suggestion to further explore the theoretical and clinical implications of safety behavior revealed a high degree of overlap and intertwining of the suggested mechanisms of action associated with a reduced use of safety behavior and other proposed mechanisms of exposure. This can be seen as a further example of the conceptual overlap or interplay between theories of change that was mentioned as a hindrance of their testing in the case study. The above updated look at quantitative mediation research indicates limited specificity, with several mediators likely implied in reciprocal causal relationships to symptom improvement, and with the likelihood that mechanisms can differ across individual cases. These results seem fully in accordance with our suggestion in the case study of Sara that mechanisms of change may be idiographic and multifaceted, with many mechanisms at work in a complex network of reciprocal causal interrelations. This state of affairs is one reason why case studies can play an important role in the study of change mechanism in psychotherapy.

In conclusion, our further reflections on the case of Sara underline the conclusions from our case study (Jensen et al., 2013) that change mechanisms in psychotherapy appear highly complex, even in a situation of a seemingly obvious and transparent example of sudden gain. Although rigorous quantitative mediational designs should be welcomed within psychotherapy research, the real clinical world may not fit nicely into a mechanical picture of specific, unidirectional causal paths-corresponding to Hume's analogy of billiard balls hitting against each other - to which much of the present quantitative research seems oriented. Rather, change patterns for individual clients may well involve a multifaceted pattern of interrelated and reciprocal causes characterized by multipotentiality and equifinality, and reflected in idiographic perspectives. Finally, it is worth noticing that, irrespective of which causal mechanisms were involved, Sara seems to have profited considerably and durably from her therapy. In a recent email to her individual therapist (VLJ) about five years after the end of treatment, she declared that she still "is feeling excellent, thanks to a very effective and successful treatment of my social phobia."

\section{REFERENCES}

Abramowitz, J. S., Foa, E. B., \& Franklin, M. E. (2003). Exposure and ritual prevention for obsessive-compulsive disorder: Effect of intensive vesrus twice-weekly sessions. Journal of Consulting and Clinical Psychology, 71, 394.

Baron, R.M. \& Kenny, D.A. (1986). The moderator-mediator variable distinction in social psychological research: Conceptual, strategic, and statistical considerations. Journal of Personality and Social Psychology, 51, 1173-1182. 
Further Reflections on the Complexities of Therapeutic

Change Mechanisms in a Case Study of Social Phobia

E. Hougaard, V.L. Jensen, \& D.B. Fishman

Pragmatic Case Studies in Psychotherapy, http://pcsp.libraries.rutgers.edu

Volume 9, Module 3, Article 3, pp. 347-358, 10-27-13 [copyright by authors]

Barlow, D.H. (1988). Anxiety and its disorders. New York: Guilford.

Barlow, D.H., Allen, L.B. \& Choate, M.L. (2004). Toward a unified treatment for emotional disorders. Behavior Therapy, 35, 205-230.

Bohni, M.K., Spindler, H., Arendt, M., Hougaard, E. \& Rosenberg, N.K. (2009). A Massed 3Week Cognitive Behavioural Group Therapy Schedule for Panic Disorder: A Comparative Study. Acta Psychiatrica Scandinavica, 119.

Bouchard, S., Gauthier, J., Nouwen, A., Ivers, H., Vallieres, A., Simard, S., et al. (2007). Temporal relationship between dysfunctional beliefs, self-efficacy and panic apprehension in the treatment of panic disorder with agoraphobia. Journal of Behavior Therapy and Experimental Psychiatry, 38, 275-292.

Casey, L. M., Oei, T. P. S., Newcombe, P. A., and Kenardy, J. (2004b). The role of catastrophic misinterpretation of bodily sensations and panic self-efficacy in predicting panic severity. Journal of Anxiety Disorders, 18, 325-340.

Clark, D.M. \& Wells, A. (1995). A cognitive model of social phobia. In: R.G. Heimberg, M.R. Liebowitz, D.A. Hope \& F.R. Schneier (eds.). Social phobia: Diagnosis, assessment and treatment. New York: Guilford Press.

Edwards, D. (2008). Handling multiple levels of data and multiple research questions in an embedded case study: Methodological challenges. Pragmatic Case Studies in Psychotherapy, Vol. 4 (4), Article 2, 53-65. Available: http://hdl.rutgers.edu/1782.1/pcsp_journal

Eells. T.D., Lombart, K.G., Kendjelic, E.M., Turner, L.C. \& Lucas, C.P. (2005). The quality of psychotherapy case formulations: A comparison of expert, experienced, and novice cognitive-behavioral and psychodynamic therapists. Journal of Consulting and Clinical Psychology, 73, 579-589.

Fentz, H.N., Arendt, M.C., O’Toole, M.S., Hoffart, A. \& Hougaard. E. (submitted). The mediational role of panic self-efficacy in cognitive behavioural therapy for panic disorder: A systematic review and meta-analysis.

Fentz, H. N., Hoffart, A., Jensen, M. B., Arendt, M., O'Toole, M. S., Rosenberg, N.K., Hougaard, E. (2013). Mechanisms of change in cognitive behaviour therapy for panic disorder: the role of panic self-efficacy and catastrophic misinterpretations. Behaviour Research and Therapy, 51 (9), 579-587.

Frankl, V.E. (1967). Psychotherapy and existentialism. Selected papers on logotherapy. New York: Washington Square Press.

Hoffart, A., Borge, F., Sexton, H., \& Clark, D. M. (2009). Change processes in residential cognitive and interpersonal psychotherapy for social phobia: A process-outcome study. Behavior Therapy, 40, 10-22.

Hofmann, S. G., \& Asmundson, G. J. G. (2008). Acceptance and mindfulness-based therapy: New wave or old hat? Clinical Psychology Review, 28, 1-16.

Hougaard, E. (2006). Kognitiv behandling af panikangst og socialfobi: En vejledning for klienter og behandlere (Cognitive-behavioral treatment for panic disorder and social phobia: A guideline for clients and therapists). Copenhagen: Dansk Psykologisk Forlag.

Hougaard, E. (2008). Further reflections on the therapy training program in aarhus, and the role of case studies in psychotherapy research. Pragmatic Case studies in Psychotherapy, Vol. 4 (4), Article 1, 1- 52. Available: http://hdl.rutgers.edu/1782.1/pcsp_journal

Hougaard, E., Madsen, S.S., Hansen, L.N., Jensen, M., Katborg, G.S., Morsaa, L., Pedersen, M., Pedersen, S.M. \& Piet, J. (2008). A novel group therapeutic format in cognitive- 
behavioral treatment for clients with social phobia in a training setting: A case study of one treatment group with nine clients. Pragmatic Case studies in Psychotherapy [Online] vol. 4 (4), 1- 52. Available at: http://pcsp.libraries.rutgers.edu/index.php/pcsp/article/view/949/2344

Huppert, J.D., Carmeli, G. \& Gilon, D. (2008). When novice therapists meet their first patients: Reflections and questions on training in CBT. Pragmatic Case Studies in Psychotherapy, Vol. 4 (4), Article 3, 66-75. Available: http://hdl.rutgers.edu/1782.1/pcsp_journal

Jensen, V. L., Hougaard, E., \& Fishman, D. B. (2013). Sara, a social phobia client with sudden change after exposure exercises in intensive cognitive-behavior group therapy: A casebased analysis of mechanisms of change. Pragmatic Case Studies in Psychotherapy. Vol. 9 (3), Article 1, 275-336. Available: http://hdl.rutgers.edu/1782.1/pcsp_journal

Kraemer, H.C., Wilson, T., Fairburn, C.G. \& Agras, W.S. (2002). Mediators and moderators of treatment effects in randomized clinical trials. Archives of General Psychiatry, 59, 877-883.

Martell, C.R., Dimidjian, S. \& Herman-Dunn, R. (2010). Behavioral activation for depression: A clinician guide. New York: Guilford Press.

McMillan, D. \& Lee, R. (2010). A systematic review of behavioral experiments vs. exposure alone in the treatment of anxiety disorders: A case of exposure while wearing the emperor's new clothes? Clinical psychology Review, 30, 467-478.

Meuret, A. E., Seidel, A., Rosenfield, D., Hofmann, S, and Rosenfield, D. (2012). Does fear reactivity during exposure predict panic symptom reduction? Journal of Consulting and Clinical Psychology, 80(5), 773-785.

Mowrer, O.H. (1960). Learning theory and behavior. New York: Wiley and Sons.

Mörtberg, E., Clark, D.M., Sundin, Ö., Wistedt, A. Å.. (2007). Intensive group cognitive treatment and individual cognitive therapy vs. treatment as usual in social phobia: A randomized controlled trial. Acta Psychiatrical Scandinavica, 115, 142-154.

NICE (2013). Anxiety disorder: Recognition, assessment and treatment. National Clinical Guideline Number 159. National Institute for Health and Clinical Excellence.

Rachman, S. (1983). The modification of agoraphobic avoidance behavior: Some fresh possibilities. Behaviour Research and Therapy, 31, 567-574.

Rachman, S., Radomsky, A. S. \& Shafran, R. (2008). Safety behaviour: A reconsideration. Behaviour Research and Therapy, 46, 163-173.

Roemer, L. \& Orsillo, S. M. (2002). Expanding our conceptualization of and treatment for generalized anxiety disorder: Integrating mindfulness/acceptance-based approaches with existing cognitive-behavioral models. Clinical Psychology: Science and Practice, 9, 54-68.

Rogojanskis, J. \& Rego, S.A. (2013). Advances and controversies in the application of a modified version of cognitive behavior therapy for social anxiety disorder. Pragmatic Case Studies in Psychotherapy, 9 (3), Article 2, 337-346. Available: http://hdl.rutgers.edu/1782.1/pcsp_journal

Salkovskis, P. M. (1991). The importance of behaviour in the maintenance of anxiety and panic: A cognitive account. Behavioural Psychotherapy, 19, 6-19.

Salkovskis, P.M., Clark, D.M. \& Gelder, M.G. (1996). Cognitive-behaviour links in the persistence of panic. Behaviour Research and Therapy, 34, 453-458.

Sloane, T. \& Telch, M.J. (2002). The effects of safety-seeking behaviour and guided threat reapprasisal of fear reduction during exposure: An experimental investigation. Behaviour Research and Therapy, 40, 235-251. 
Smits, J. A., Julian, K., Rosenfield, D., and Powers, M. B. (2012). Threat reappraisal as a mediator of symptom change in cognitive-behavioral treatment of anxiety disorders: a systematic review. Journal of Consulting and Clinical Psychology, 80(4), 624-635.

Stangier, U., Heidenreich, T., Peitz, M., Lauterbach, W. \& Clark, D.M. (2003). Cognitive therapy for social phobia: Individual versus group treatment. Behavior Research and Therapy, 41, 991-1007.

Twaites, R. \& Freeston, M.H. (2005). Safety-seeking behaviours: fact or fiction? How can we clinically differentiate between safety behaviours and adaptive coping strategies across anxiety disorders? Behavioural and Cognitive Psychotherapy, 33, 177-188.

Zegal, Z.V., Williams, M.G. \& Teasdale, J.D. (2002). Mindfulness-based cognitive therapy for depression: A new approach to preventing relapse. New York: Guilford. 
Pragmatic Case Studies in Psychotherapy, http://pcsp.libraries.rutgers.edu

Volume 9, Module 3, Article 3, pp. 347-358, 10-27-13 [copyright by authors]

\section{Figure 1. Baron and Kenny’s (1986) Mediational Model}

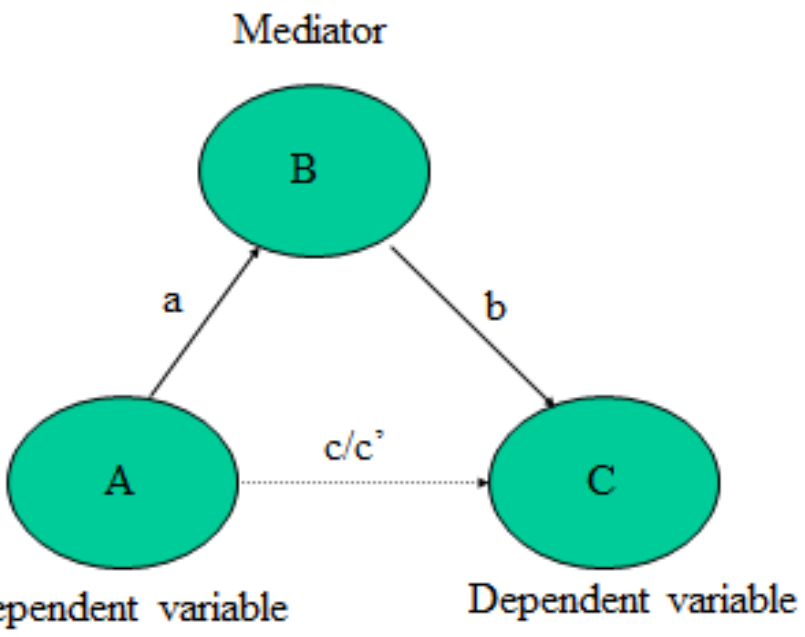

